\title{
Peertechz
}

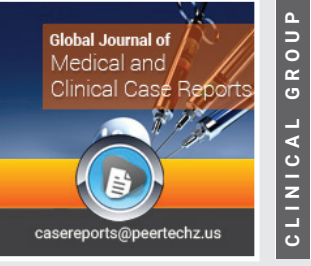 \\ Medical and Clinical Case Reports}

\section{To study prevalence of ankle and foot complex injuries in recreational barefoot and shod}

\section{marathon runners: A cross-}

Received: 21 July, 2021

Accepted: 08 September, 2021

Published: 09 September, 2021

*Corresponding author: Sanjana Gandhi, Bachelor of Physiotherapy, Dr. DY Patil Deemed to be University, Pune, India, Tel: +91 8408823687;

E-mail: san.gan.bpt16@dypatil.edu

Keywords: Ankle and foot complex injuries; Marathon runners; Physical therapy; Rehabilitation

https://www.peertechzpublications.com

\section{Check for updates}

\section{sectional study}

\section{Sanjana Gandhi ${ }^{1 *}$ and Summaiya Zareen Shaikh ${ }^{2}$}

${ }^{1}$ Bachelor of Physiotherapy, Dr. DY Patil Deemed to be University, Pune, India

${ }^{2}$ Ph.D. Scholar, Assistant Professor, Dr. D.Y. Patil Deemed to be University, India

\begin{abstract}
Background: Injuries occurring while running barefoot and shod has been a topic of concern for a long time due to the increased interest in recreational running. This research focused on the ankle and foot complex injuries in shod and barefoot running groups. The objective was to find the pattern of ankle and foot complex injuries and if any other aspects such as type of running or the frequency of training for marathons affect the occurrence of injuries.
\end{abstract}

Methodology: 100 participants (83 shod and 17 barefoot) between the age of 18-60 years filled a self-made questionnaire on ankle and foot related injuries via electronic medium (Google form).

Results: Plantar fasciitis, ankle sprain and peroneal tendinitis are the most common injuries in the ankle and foot complex. This can be attributed to by the reduced training frequency leading to ankle sprain and peroneal tendinitis. Majority participants were found to have a rearfoot strike pattern attributing to an increased risk of plantar fasciitis.

Conclusion: Ankle sprain, plantar fasciitis, peroneal tendonitis, flat feet and metatarsal stress fractures are most commonly occurring. More research on this topic is encouraged with objective measurements.

\section{Introduction}

Human race has been habituated to barefoot walking and running since time immemorial. Earliest recorded evidence of foot wear usage dates back to 8300 years, however, the modern running shoes were invented around the 1970s. Since the latter part of the 2oth century, running has become a popular sport around the world [1]. There are various types of injuries caused in both the groups of marathon runners. Eighty percent of running disorders are overuse injuries resulting from a mismatch between the resilience of the connective and supporting tissue and running [2]. Common injuries are: ankle stress fractures, Achilles tendinopathy, peroneal tendinopathy,tibialis posterior tendinopathy and tibialis anterior tendinopathy [3].
$5 \%$ of stress fractures of the foot and ankle occur in the metatarsals, predominantly affecting the first and second metatarsals. $30 \%$ affect the lateral malleolus and $9 \%$ the medial malleolus. The calcaneus, talus, navicular and sesamoid account for the remaining $6 \%$.

Plantar Fasciitis (PF) is among the most common causes of heel pain in athletes, usually presenting as a sharp pain in the middle of the heel or foot arch. Achilles tendon injuries account for approximately $7 \%$ of running injuries and occur more commonly in males. It also affects predominantly runners with many years of experience.Ankle sprains are the most common injuries in sports, representing $40 \%$ of all injuries. Ankle sprains represent approximately $1 \%$ of running related injuries. The majority of ankle sprains occur on the lateral 
side and correspond to an ankle inversion injury [4]. Overall, women were at lower risk than men for sustaining runningrelated injuries. Strong and moderate evidence was found that a history of previous injury and of having used orthotics/inserts was associated with an increased risk of running injuries. Age, previous sports activity, running on a concrete surface, participating in a marathon, weekly running distance (3039 miles) and wearing running shoes for 4 to 6 months were associated with a greater risk of injury in women than in men [5]. There are several differences between barefoot and shod marathon runners. When comparing barefoot and shod running we realise that there are differences in foot strike patterns for barefoot and shod running. Barefoot endurance runners have more of a Forefoot Strike (FFS) or Midfoot Strike (MFS) rather than rear foot (RFS). In shod runners rearfoot strike is a more predominant pattern [1]. Approximately $90 \%$ of shod runners' land on their heels [6]. The effects of barefoot running on loading rate appear dependent on strike pattern adopted, with a forefoot strike pattern found to reduce loading rate, whilst a rearfoot strike pattern increases loading rate when running barefoot compared to shod [7]. In addition to a forefoot strike pattern, barefoot running also affords the runner increased sensory feedback from the foot-ground contact, as well as increased energy storage in the arch [1]. Barefoot runners have reduced stride length, increased stride rate and reduced foot contact time. There is less impact force in barefoot runners, and long distance runners [1].

Barefoot running is associated with reduced peak Ground Reaction Force (GRF), increased foot and ankle plantar flexion and increased knee flexion at ground contact compared with running in a neutral shoe [7]. Although running has many known health benefits, it also poses significant risk for injury. van Gent et al. conducted a systematic literature review of injuries in non-elite recreational and competitive long-distance runners. They reported lower extremity injury incidence varying from $19.4 \%$ to $79.3 \%$, with the foot accounting for $5.7 \%$ to $39.3 \%$ of injuries. This article will discuss running injuries of the ankle and foot complex commonly encountered by the sports physical therapist and on barefoot (or minimal footwear) running because this recently has become a topic of interest among runners [8]. Something about the act of running barefoot may tend to limit how much people run. For example, the barefoot group reported a total of 57 injuries to their soles, such as cuts, blisters, bruises and stubbed toes; those in shoes reported only eight types of injuries [3]. There have been a lot of studies about the kinematics of the ankle joint and its relation with respect to the possibility of ankle and injuries in barefoot and shod runners and there has also been a lot of study about the type of training which causes a hip or knee joint injury in marathon runners but less studies have been conducted on the prevalence of ankle and foot complex injuries in marathon runners. This study will help plan a better training strategy, type and frequency of training and will also help plan a prevention strategy for the same. There were some differences in the type of injuries: the barefoot group appeared to be more vulnerable to calf injuries, while the shod group suffered more knee and hip injuries, but the small numbers of each type of injury make it difficult to draw any firm conclusions [3]. To find out these types of injuries and come to a conclusion on which injuries occur in barefoot and shod runners, this study is needed.

The aim of the study was to find the prevalence of ankle and foot complex injuries in shod and barefoot marathon runners. The sub-objectives of the study were to find the following:

1. Pattern and spread of the ankle and foot complex injuries in barefoot and shod runners.

2. Identification of contributing factors to an ankle and foot complex injury and what part thereof can be attributed to the runner being barefoot or shod.

3. To study the types of injuries pertaining to a marathon runner's preference of running barefoot or shod.

\section{Methodology}

100 participants were included in this cross-sectional study. The study population were divided into two groups i.e. $21 \mathrm{k}$ half \& $42 \mathrm{k}$ full marathon runners using a self- made questionnaire using random sampling. Included participants had to have a minimum of 1-year experience with $21 \mathrm{kms}$ and $42 \mathrm{kms}$ of marathon running, age between 18-60 years whereas any major injuries not pertaining to the study, Pathological reasons contributing to the cause of injury were excluded from the study. A written informed consent form was taken from the participants. The study was conducted between November 2019 to August 2020.

\section{Results}

1. Distribution according to age

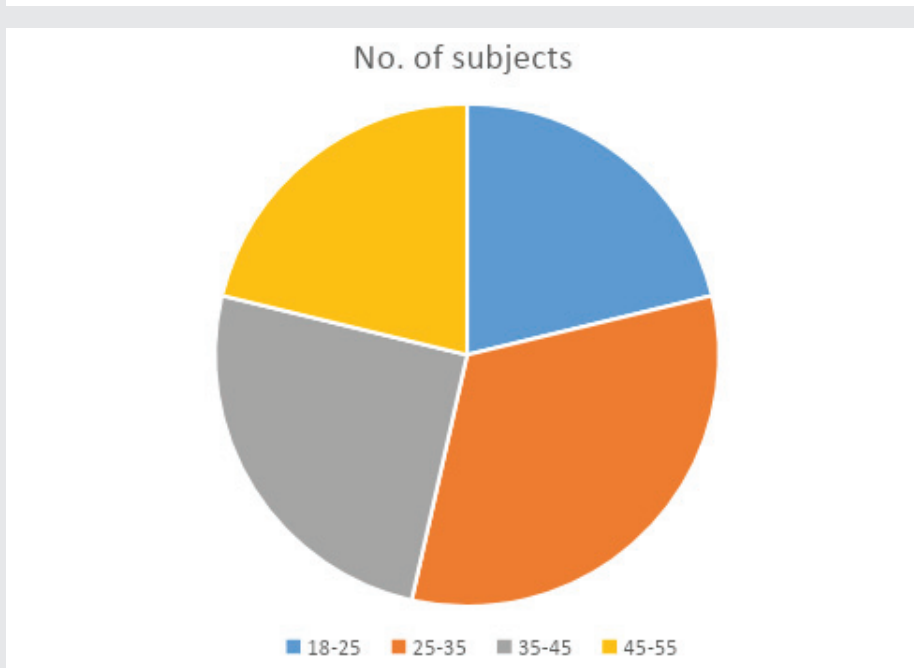

Table 1:

\begin{tabular}{|c|c|c|}
\hline Age & No. of subjects & Percentage \\
\hline $18-25$ & 21 & $21 \%$ \\
\hline $25-35$ & 32 & $32 \%$ \\
\hline $35-45$ & 25 & $25 \%$ \\
\hline $45-55$ & 21 & $21 \%$ \\
\hline $55-60$ & 1 & $1 \%$ \\
\hline
\end{tabular}




\section{Inference}

According to Table 1, 21 out of 100 participants are aged between $18-25$, making 21\%, 32 participants between 25-35, making $32 \%$, 35 participants between $35-45$, making $25 \%$, 21 participants between $45-55$, making $21 \%$ and 1 participant between 55-60, making it $1 \%$.

2. Distribution according to number of years running marathons and whether running shod (with shoes) and/or barefoot.

\begin{tabular}{|c|c|r|}
\hline No. of years & No. of subjects & Percenta \\
\hline $0-1$ & 3 & $3 \%$ \\
\hline $1-2$ & 24 & $24 \%$ \\
\hline $2-4$ & 31 & $31 \%$ \\
\hline $4-5$ & 15 & $15 \%$ \\
\hline $5+$ & 27 & $27 \%$ \\
\hline & & \\
\hline & & $83 \%$ \\
\hline With shoes & 83 & $17 \%$ \\
\hline Without shoes & 17 & \\
\hline
\end{tabular}

\section{Inference}

According to Table 1, 3 participants run marathons since 1 year, making it 3\%, 24 participants since $1-2$, making it $24 \%$, 31 participants since $2-4$ years making it 31\%, 15 participants since 4-5 years making it $15 \%$ and 27 participants since $5+$ years, making it $27 \%$. According to Table 2, 83 participants run with shoes making it $83 \%$ and 17 participants run bare feet making it $17 \%$.

3. Distribution according to frequency of training and whether they have had an ankle and foot complex injury or not

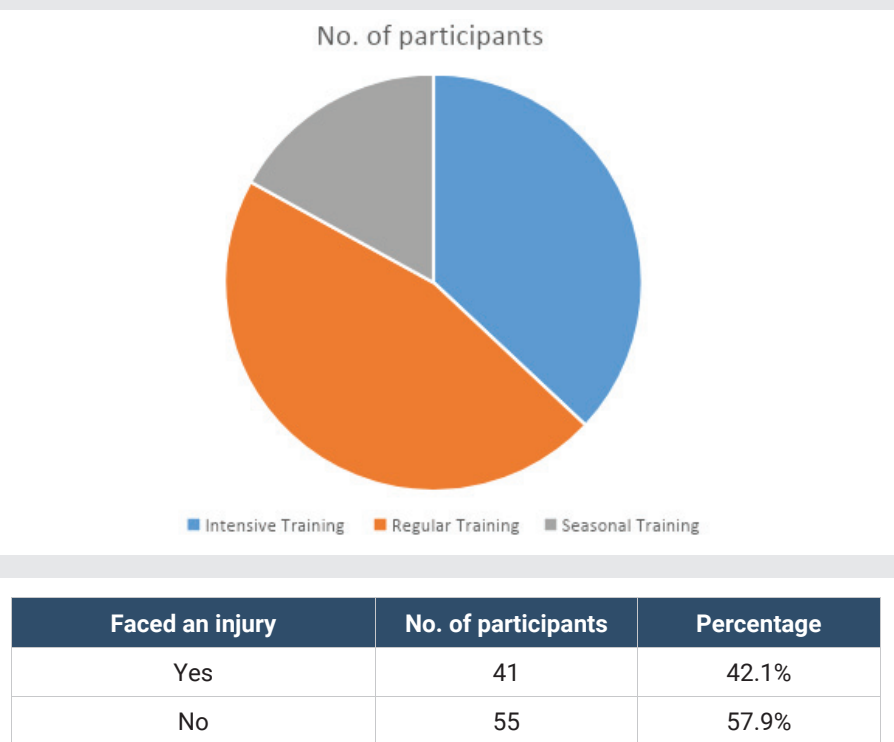

Inference

According to pie chart 1, 37 participants undergo intensive training(everyday), making it 37\%, 46 participants undergo regular training, making it 46\%, 17 participants undergo seasonal training, making it $17 \%$.

According to table 1, 41 participants faced an injury making it $42.1 \%$ and 55 participants did not face an injury, making it $57.9 \%$.

4. Distribution on the nature of injury of shod (with shoes) marathon runners

Types of injuries occuring in shod marathon runners

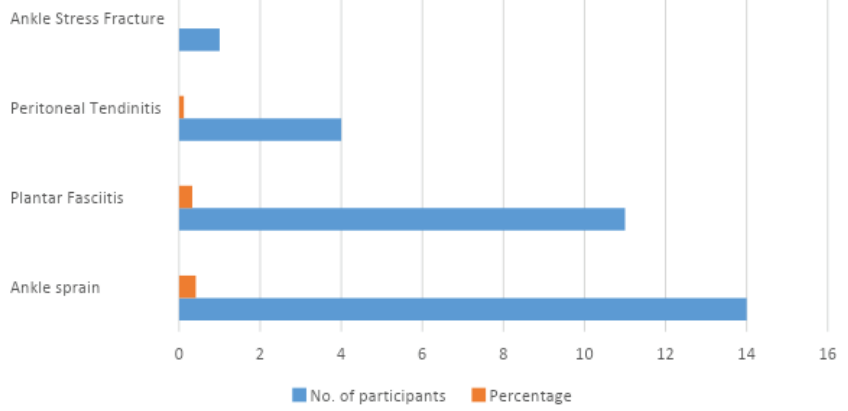

Table 1:

\begin{tabular}{|l|l|l|}
\hline Type of injury & No. of participants & Percentage \\
\hline Ankle sprain & 14 & $41.17 \%$ \\
\hline Plantar Fasciitis & 11 & $32.35 \%$ \\
\hline Peroneal Tendonitis & 4 & $11.76 \%$ \\
\hline Ankle Stress Fracture & 1 & $0.02 \%$ \\
\hline
\end{tabular}

Table 2:

\begin{tabular}{|l|l|l|}
\hline Metatarsal crush injury & 1 & $0.02 \%$ \\
\hline Foot ligament tear & 1 & $0.02 \%$ \\
\hline Flat Feet & 1 & $0.02 \%$ \\
\hline Cartilage damage & 1 & $0.02 \%$ \\
\hline
\end{tabular}

\section{Inference}

According to the above table and bar graph, 14 participants suffered from ankle sprain, making it $41.17 \%$, 11 participants suffered from Plantar fasciitis, making it 32.35\%, 4 participants suffered from Peroneal Tendonitis making it $11.76 \%$, and 1 person each for ankle stress fracture, metatarsal crush injury, foot ligament tear, flat feet and cartilage damage, making it $0.02 \%$.

5. Distribution of the number of years' participants have been running barefoot and the frequency of training in the transition phase from shod to barefoot

Table 1:

\begin{tabular}{|c|c|c|}
\hline No. of years & No. of participants & Percentage \\
\hline $0-1$ & 4 & $22.2 \%$ \\
\hline $1-2$ & 3 & $16.7 \%$ \\
\hline $2-4$ & 4 & $22.2 \%$ \\
\hline $4-5$ & 3 & $16.7 \%$ \\
\hline $5+$ & 4 & $22.2 \%$ \\
\hline
\end{tabular}


Table 2:

\begin{tabular}{|l|l|l|}
\hline Type & No. of participants & Percentage \\
\hline Intensive Training & 3 & $16.7 \%$ \\
\hline Regular Training & 15 & $83.3 \%$ \\
\hline Seasonal Training & 0 & 0 \\
\hline
\end{tabular}

\section{Inference}

According to Table 1, 4 participants have practiced running bare feet for 1 year, making it $22.2 \%, 3$ participants for 1-2 years, making it $16.7 \%$, 4 participants for $2-4$ years, making it $22.2 \%$, 3 participants for $4-5$ years making it $16.7 \%, 4$ participants been practicing since $5+$ years making it $22.2 \%$ According to Table 2, 3 participants underwent intensive training, making it $16.7 \%$, 15 participants underwent regular training making it $83.3 \%$ and o participants who ran bare feet underwent seasonal (only before marathons).

6. Distribution of number of participants who have faced an injury while running barefoot and the nature of injury

\section{Table 1:}

\begin{tabular}{|c|c|c|}
\hline Had an injury & No. of participants & Percentage \\
\hline Yes & 9 & $56.3 \%$ \\
\hline No & 7 & $43.8 \%$ \\
\hline
\end{tabular}

Type of injuries occuring in barefoot runners

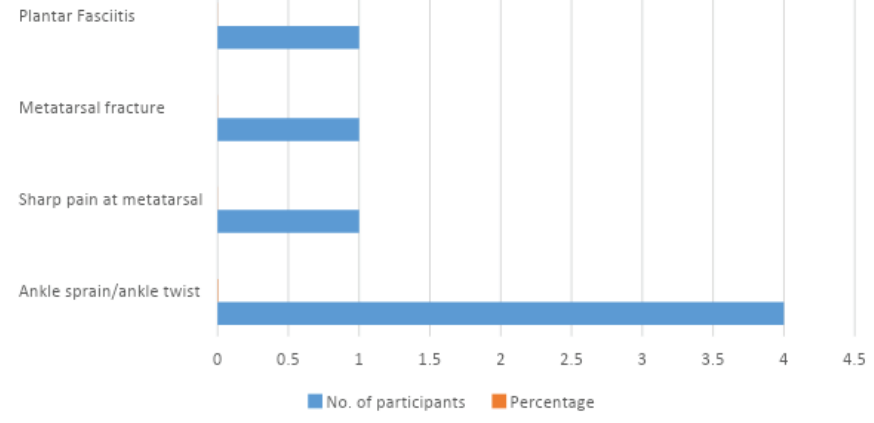

Table 2

\begin{tabular}{|c|c|c|}
\hline Nature of injury & No. of participants & Percentage \\
\hline Ankle sprain & 4 & $0.44 \%$ \\
\hline Sharp pain at metatarsal & 1 & $0.11 \%$ \\
\hline Metatarsal fracture & 1 & $0.11 \%$ \\
\hline Plantar Fasciitis & 1 & $0.11 \%$ \\
\hline Peroneal Tendonitis & 1 & $0.11 \%$ \\
\hline General bruises & 1 & $0.11 \%$ \\
\hline
\end{tabular}

\section{Inference}

According to Table 1, 9 out of 16 participants faced an injury, making it 56.3\%, and 7 participants did not face an injury, making $43.8 \%$.

According to Table 2, 4 participants out of 9 suffered from ankle sprain making it $0.44 \%, 1$ person each faced sharp pain at metatarsal, metatarsal fracture, plantar fasciitis, peroneal tendonitis and general bruises, making it $0.11 \%$ for each of these 5 .

\section{Discussion}

The aim of this study is to find the prevalence of ankle and foot complex injuries in barefoot and shod marathon runners. The study was conducted at random amongst 100 marathon runners, running full $(42 \mathrm{k})$ and half $(21 \mathrm{k})$ marathons. The participants were from different age groups. There was no specific requirement as to where they train and hence all training terrains were accepted and taken into consideration for the study. The key findings of this study are ankle sprain, plantar fasciitis and peroneal tendonitis as most commonly occurring injuries. The goal was to determine the number of and type of ankle and foot complex injuries occurring in these two groups and the goal was not to compare the two groups in any way.

The study successfully takes into account the two types of population which have undergone ankle and food complex injuries which is 44 out of $100,44 \%$ of the population. The study had a mixed population of males and females; people of different occupations and did not differentiate in the type of work the participants did, but included the frequency of training (how many times in a week) and type of training (vigorous, light, occasional) the participants usually did. Studies - Running Injuries: Barefoot, Minimalist Shod and Shod Running- Dr. Manoj Kumar [1], state that in shod marathon runners, rearfoot strike pattern is more commonly seen, which shows why many shod marathon runners, particularly 11 out of 34, complained of plantar fasciitis injury and heel pain. Flat feet, which is also a common precursor to plantar fasciitis was also an injury reported by 1 of the 34 participants in the injury. Since these participants were chosen at random, their other pathological conditions which might attribute to these injuries such as obesity, high arches, tightness of muscles were not taken into consideration.

The occurrence and rates of injuries have been studied by Peter Larson [9] and he states that foot and ankle injuries vary a lot with the vertical impact peak of barefoot and shod runners. According to him, the vertical impact peak (vertical ground reaction force resulting from initial contact of heel with the ground [9]) is reduced or almost absent in forefoot strikers as compared to heel strikers which also attributes to the fact that heel strikers/rare foot strikers have an increased risk of plantar fasciitis.Ankle sprain is the common and most occurring injury in the two groups, particularly 14 in shod runners and 4 in barefoot runners. According to this study, the training frequencies of both the group of participants was majorly regular (weekly, bi-weekly) and not intensive(training everyday). Certain exercises such as balance training, strengthening are an integral part of intensive training. Ankle sprain being a ligament injury (lateral ankle sprain being the commonest), attributes to lack of intensive training in marathon runners of both the groups. According to study- The effects of isolated ankle strengthening and functional balance training on strength, running mechanics, postural control and injury prevention in novice runners: design of a randomized controlled trial- Jennifer Baltich, et al. [10], it is stated that, 
regular strengthening of the large and small muscles around the ankle joint results in equal distribution of small muscles and use of those muscles.

Furthermore, since most of the subjects have either a sedentary or a moderately active lifestyle, it can also be a cause of increased ankle sprain due to reduced ankle and foot muscle strengthening.Although, more research needs to be done regarding the effects of ankle and foot training on injuries.Another common injury-peroneal tendonitis, occurs in 4 participants in shod runners and in 1 participant running barefoot. The lack of more barefoot runner participants favours certain injuries to be more in shod running when according to external evidence the number should be almost the same for such certain injuries.Commonly classified as an overuse injury, peroneal tendonitis was surprisingly found in only 5 out of 100 participants making it not so common. It can also be stated that, since the number of intensive trainers are less in this study, the number of participants running/training everyday were less, not causing any particular overuse in those participants and hence peroneal tendonitis was not a common finding.A forefoot striking pattern is suspected to cause peroneal tendonitis. According to a study done by Pejman Ziai, et al. [11], peroneal tendonitis can predispose ankle sprain. This supports the results from Table 1 , of point 4 , stating why the ankle sprain injuries were more in number due to the number of peroneal tendinitis being more in shod runners as compared to barefoot runners.Other findings focus on injuries which according to this study are uncommon and found only in one individual in both the groups of marathon runners. More research on this topic and the topic concerning trainingfrequency of training and type of training is majorly suggested to understand the predisposing factors of these injuries in order for a physiotherapist to plan a treatment [12-14].

\section{Clinical implications}

This study will help physiotherapists in planning a treatment, by taking into account the frequency of training (number of times a marathon runner trains in a week) in marathon runners. An ICF takes into consideration components, such as personal facilitators and barriers, which include the patient's specific strengths and weaknesses. According to the discussions above, the type of training heavily dictates the type of injury faced by a marathon runner- more the training, less the chances of an injury. Hence the data provided by the type of training, can help indicate the strengths of a patient and his/ her tolerance to exercise, alongside the clinical examination of strength and manual muscle testing by the physiotherapist Other research studies do not include the type of training adopted by each marathon runner, and hence this study can be prospective. Changing the type of running, changes the foot strike pattern and ground reaction force. Whether these components affect the prevalence of injuries changes from subject to subject. A form of basis can be formed for another study, if conducted, for theoretical purposes, to study and assess how the foot strike pattern and ground reaction force affect the prevalence of injuries in barefoot and shod marathon runners.

\section{Conclusion}

Short term and long term effects of an ankle and foot complex injury remains a runners' concern. This study suggests that certain types of injuries such as ankle sprain, plantar fasciitis, peroneal tendonitis, flat feet and metatarsal stress fractures are most commonly occurring. A solution and plan of treatment of these injuries after studying the different trails, types of training, should be done. In addition to the need of proper study for the training methods, terrain of training, a proper study on the pathology and skeletal causes such as obesity or high arches should be done while studying these injuries and planning treatment.

\section{Limitations}

1. Marathon runners running $10 \mathrm{k}$ were not included in the study as well as runners who run $42 \mathrm{k}$ and above (ultra marathon runners) due to differences in their training styles-plyometric running, and different terrain of training (example- trail running).

2. Marathon runners below the age of 18 and above the age of 60 were not included because they have a different lifestyle as the ones below 18 are in school or college and ones above 60 are mostly retired.

3. Pathological or musculoskeletal causes such as having an ongoing disease or having long arches of the foot have not been taken into consideration, neither has the tightness, strength or level of fatigue for each individual's muscles been accounted for.

4. Type of shoes worn by marathon runners or their preference in shoe branding has not been included in the study.

\section{References}

1. Nair MK (2019) Running Injuries: Barefoot, Minimalist Shod and Shod Running J Rheumatol Res 1: 5-9. Link: https://bit.ly/3tpgzc2

2. van der Worp MP, ten Haaf DS, van Cingel R, de Wijer A, Nijhuis-van der Sanden MW, et al. (2015) Injuries in Runners; A Systematic Review on Risk Factors and Sex Differences. PLoS One 10: e0114937. Link: https://bit.ly/3DWVdaY

3. Hutchinson A (2018) Special to the globe and Mail. Link: https://tgam.ca/2YBzhSu

4. Pelletier-Galarneau M, Martineau P, Gaudreault M, Pham X (2015) Review of running injuries of the foot and ankle: clinical presentation and SPECTCT imaging patterns. Am J Nucl Med Mol Imaging 5: 305-316. Link: https://bit.ly/3h8ZbTW

5. van der Worp MP, ten Haaf DS, van Cingel R, de Wijer A, Nijhuis-van der Sanden MW, et al. (2015) Injuries in Runners; A Systematic Review on Risk Factors and Sex Differences. PLoS One 10: e0114937. Link: https://bit.ly/3BRhC7I

6. Sun X, Yang Y, Wang L, Zhang X, Fu W (2018) Do Strike Patterns or Shoe Conditions have a Predominant Influence on Foot Loading. J Hum Kinet 64 13-23. Link: https://bit.ly/2X3Pqiw

7. Hall JP, Barton C, Jones PR, Morrissey D (2013) The Biomechanica Differences Between Barefoot and Shod Distance Running: A Systematic Review and Preliminary Meta-Analysis. Sports Med 43: 1335-1353. Link: https://bit.ly/3/4mwaz

8. Kindred J, Trubey C, Simons SM (2011) Foot Injuries in Runners. Curr Sports Med Rep 10: 249-254. Link: https://bit.ly/2WVIK6e

Citation: Gandhi S, Shaikh SZ (2021) To study prevalence of ankle and foot complex injuries in recreational barefoot and shod marathon runners: A cross- sectional 
9. Larson $P$ (2012) Foot strike in runners: Influence on injury risk. Link: https://bit.ly/3hcYsBd

10. Baltich J, Emery CA, Stefanyshyn D, Nigg BM (2014) The effects of isolated ankle strengthening and functional balance training on strength, running mechanics, postural control and injury prevention in novice runners: design of a randomized controlled trial. BMC Musculoskelet Disord 15: 407. Link: https://bit.ly/2X6XQGv

11. Ziai P, Benca E, Wenzel F, Schuh R, Krall C, et al. (2016) Peroneal Tendinosis as a Predisposing Factor for the Acute Lateral Ankle Sprain in Runners. Knee Surg Sports Traumatol Arthrosc 24: 1175-1179. Link: https://bit.ly/3hcwOnO
12. Monaldi $M$, Alters $M$, Bowen CM, Corlew BR, Halmich $R$, et al. (2019) Biomechanic Analysis of Barefoot vs. Shod Running. Link: https://bit.ly/3tl6r44

13. Ankle injuries - how do they happen, how can you prevent them and can you run on them. Link: https://bit.ly/3A0FuoY

14. Altman AR, Davis IS (2012) Barefoot Running: Biomechanics and Implications for Running Injuries. Curr Sports Med Rep 11: 244-250. Link: https://bit.ly/3jSXyf2

\section{Discover a bigger Impact and Visibility of your article publication with}

\section{Peertechz Publications}

\section{Highlights}

* Signatory publisher of ORCID

* Signatory Publisher of DORA (San Francisco Declaration on Research Assessment)

* Articles archived in worlds' renowned service providers such as Portico, CNKI, AGRIS, TDNet, Base (Bielefeld University Library), CrossRef, Scilit, J-Gate etc.

* Journals indexed in ICMJE, SHERPA/ROMEO, Google Scholar etc.

* OAI-PMH (Open Archives Initiative Protocol for Metadata Harvesting)

* Dedicated Editorial Board for every journal

* Accurate and rapid peer-review process

* Increased citations of published articles through promotions

* Reduced timeline for article publication

Submit your articles and experience a new surge in publication services (https://www.peertechz.com/submission).

Peertechz journals wishes everlasting success in your every endeavours.

Copyright: @ 2021 Gandhi S, et al. This is an open-access article distributed under the terms of the Creative Commons Attribution License, which permits unrestricted use, distribution, and reproduction in any medium, provided the original author and source are credited.

Citation: Gandhi S, Shaikh SZ (2021) To study prevalence of ankle and foot complex injuries in recreational barefoot and shod marathon runners: A cross- sectional study. Glob J Medical Clin Case Rep 8(3): 099-0104. DOI: https://dx.doi.org/10.17352/2455-5282.000139 